\title{
Comparison of experimental and computational study of the fluid dynamics in fluidized beds with agglomerates
}

\author{
Nora C I S Furuvik Rajan Jaiswal Britt M E Moldestad \\ Department of Process, Energy and Environmental Technology, University of South-Eastern Norway, Norway, \\ \{nora.c.i.furuvik, rajan.jaiswal, britt.moldestad\}@usn.no
}

\begin{abstract}
Particle agglomeration is one of the obstacles for successful application and commercial breakthrough of fluidized bed biomass gasification. The problem is generally associated with molten ash components that interact with the bed particles, forming agglomerates that interfere with the flow behavior.

In this work experimental and computational study are combined in order to gain more insight into the fluid dynamics in a bubbling fluidized bed gasifier. The goal is to develop a Computational Particle Fluid Dynamic (CPFD) model that can be used in further investigations of the correlation between flow behavior and bed agglomeration during biomass gasification in fluidized beds. The experimental part was performed in a $20 \mathrm{~kW}$ laboratory scale bubbling fluidized bed system. The commercial CPFD software Barracuda Virtual Reactor (VR) version 17.4.1 was used for the computational study. Simulation results were compared to the experimental data in order to validate the CPFD model. Pressure drops predicted by the simulations were in good agreement with the experimental measurements, which indicate that the model is well capable of studying the fluid dynamics in a fluidized bed system.
\end{abstract}

Keywords: $\quad$ biomass gasification, fluidized bed, agglomeration, CPFD simulations

\section{Introduction}

Fluidized bed reactors have a broad use in various industrialized applications and are common in both petroleum and petrochemical processes, as well as heat and power production. A typical fluidized bed system consists of a cylindrical column packed with a suitable bed material, which is kept in a fluidized state by passing a fluid through at a velocity that is sufficiently high to "loosen" the bed particles. The fluidized bed design allows for good mixing in all directions within the reactor, resulting in enhanced fuel/fluid contact and thereby increased heat and mass transfer (Sansaniwal, 2017). As a result of the combination of intense solid mixing and bed materials with large thermal capacity, the fluidized beds can be operated under nearly isothermal conditions. Additionally, they have the benefit of continuous and controlled operations (Basu, 2013). Due to their homogenous operation conditions, the fluidized bed reactors are capable of handling a wide range of fuels, and compared to other conversion technologies they are considered well suited for processing highly reactive fuels such as biomass (Basu, 2013; Capareda, 2014).

Despite the many advantages with the fluidized beds, some difficulties are reported related to the gasification process of biomass-derived fuels. Generally, these problems are associated with ash-melting and following agglomeration of bed material. Biomass fuels refer to a broad variety of feedstock, and are characterized as heterogeneous with widely varying chemical and physical properties (Capareda, 2014). Due to the differences in chemical and physical properties, the biomass fuel characteristics are associated with diversity in composition of ash forming elements, which may represent significant barriers for successful fluidized bed gasification processes (Tiffault et al, 2018).

Understanding the fluid dynamics in the fluidized bed is essential for maintaining ideal operational conditions for an appropriate fluidized regime. This work is divided into one experimental part and one simulation part. The experimental setup is a $20 \mathrm{~kW}$ laboratory scale bubbling fluidized bed gasifier. The laboratory scale model is used to study the fluidized conditions at different gasification temperatures. Additional experiments with a mix of bed material and agglomerates are performed to investigate the dependence of fluidization on particle shape, size and density. For the simulation part, the commercial CPFD software Barracuda VR version 17.4.1 is used for simulations of the flow behavior in a bubbling fluidized bed gasifier. The data and measurements achieved from the fluidization experiments are used to develop and validate a CPFDmodel that can be used for further investigations.

\section{Particle agglomeration in fluidized beds}

Ash related problems are a key concern in gasification of biomass in fluidized beds. The problems are generally related to alkali ash components that interact with the bed particles, forming agglomerates that cause fluid dynamic disturbances in the bed. The agglomerates interfere with the flow behavior, change the fluidized conditions and make further fluidization impossible. During bed agglomeration processes, the solid mixing becomes ineffective because the agglomerates tend to 
obstruct the particles movement, resulting in decreased heat transfer and local temperature deviations that in turn create de-fluidized volumes in the bed (Bartles et $a l, 2008)$. De-fluidization is described as a total collapse of the fluidized bed, and is recognized by a rapidly decreasing bed pressure drop and/or a substantial change in the bed temperature. In the most severe cases, particle agglomeration results in unscheduled shutdowns of the whole installation (Öhman and Nordin, 2000).

Particle agglomeration in fluidized bed biomass gasification is highly coupled to the high temperature chemistry of the biomass ash, i.e. its melting and the consequently appearance of an alkali liquid phase that glue the ash to the surface of the bed particles (Öhman et al., 2000). The mechanisms are dominated by a combination of ash particles attaching the surface of the bed material and chemical reactions that occur between the ash-coated bed particles and the condensed gaseous alkali components (Figure 1).

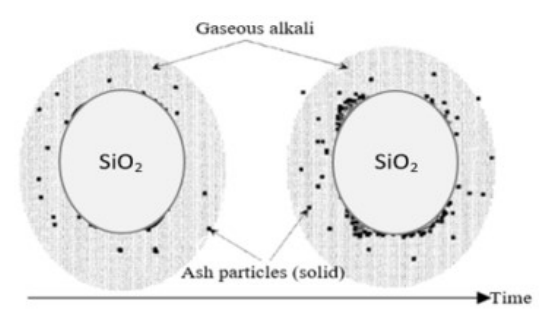

Figure 1. Ash deposition onto the surface of silica sand bed material (Öhman et al., 2000).

As a consequence of repeated collisions between the ash-coated particles in the bed, the particles stick together and eventually they grow towards larger agglomerates. Figure 2 shows a photo of agglomerate formed during gasification experiments with grass pellets in a bubbling fluidized bed gasifier (Furuvik et $a l, 2020)$.

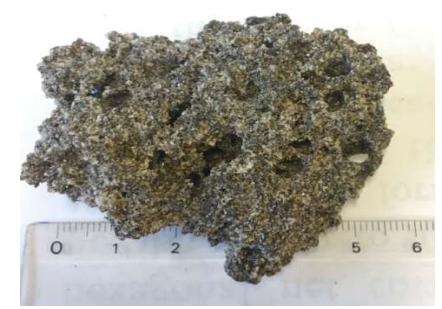

Figure 2. Agglomerate of biomass ash and silica sand particles, formed in a bubbling fluidized bed gasifier.

\section{Experimental setup}

The fluidization experiments were performed in a 20 $\mathrm{kW}$ laboratory scale bubbling fluidized bed reactor with a height of $100 \mathrm{~cm}$ and an inner diameter of $10 \mathrm{~cm}$. A schematic of the experimental setup is shown in Figure 3. The fluidizing agent was air introduced into the bed through two pipes from the bottom of the column. The air mass flow rate was controlled with a Brook air flowmeter, with an operating range between $0.5 \mathrm{~kg} / \mathrm{h}-$ $4.7 \mathrm{~kg} / \mathrm{h}$. Five pressure transducers placed along the height of the reactor were constantly monitoring the operating conditions in the bed. Each pressure transducer measures the gauge pressure in the given position, i.e. the fluid pressure above the atmospheric pressure. The temperature and pressure sensors are connected to the LabVIEW software for data acquisition. The locations of the pressure and temperature sensors (P1/T1, P2/T2, P3/T3, P4/T4 and $\mathrm{P} 5 / \mathrm{T} 5)$ are seen in Table 1.



Figure 3. Schematic of the laboratory scaled bubbling fluidized bed used in fluidization experiments.

Silica sand particles with a mean diameter of $305 \mu \mathrm{m}$ and particle density $2600 \mathrm{~kg} / \mathrm{m}^{3}$ were used as bed material. The sand particles were preheated to the operating temperature by letting the air pass through a preheated chamber before entering the reactor. The experiments were run without feeding biomass to the reactor. The externally heated reactor was operated at temperatures that were kept constant throughout each test run. Five thermocouples were used to determine the temperature profile in the bed and to control the temperatures at experimental conditions of $300^{\circ} \mathrm{C}$, $600^{\circ} \mathrm{C}, 700^{\circ} \mathrm{C}$ and $800^{\circ} \mathrm{C}$. For each temperature, a fluidization experiment of the bed particles were performed. The pressure drop in the bed were recorded at different superficial air velocities ranging from 0.029 to $0.330 \mathrm{~m} / \mathrm{s}$. The superficial air velocities $\left(u_{f}\right)$ were calculated from the mass flow rate $(\dot{m})$, the area of the reactor $(A)$ and the air density at the specific temperatures $\left(\rho_{f}\right)$ :

$$
u_{f}=\frac{\dot{m}}{A \cdot \rho_{f}}
$$

Table 1 lists the operating parameters for the bubbling fluidized bed reactor. The minimum fluidization velocity for each experimental condition was calculated using the equation for minimum fluidization derived from Ergun's equation (Kuuni and Levenspiel, 1991). 
Table 1. Operating parameters for fluidization experiments.

\begin{tabular}{|l|l|}
\hline Description & Value \\
\hline $\begin{array}{l}\text { Operating } \\
\text { temperatures }\end{array}$ & $300,600,700$ and $800^{\circ} \mathrm{C}$ \\
\hline Air flow rate & $0.5-3.0 \mathrm{~kg} / \mathrm{h}$ \\
\hline & $0.029-0.172 \mathrm{~m} / \mathrm{s} @ 300^{\circ} \mathrm{C}$ \\
Superficial air & $0.044-0.262 \mathrm{~m} / \mathrm{s} @ 600^{\circ} \mathrm{C}$ \\
velocity range & $0.049-0.292 \mathrm{~m} / \mathrm{s} @ 700^{\circ} \mathrm{C}$ \\
& $0.054-0.330 \mathrm{~m} / \mathrm{s} @ 800^{\circ} \mathrm{C}$ \\
\hline & $0.050 \mathrm{~m} / \mathrm{s} @ 300^{\circ} \mathrm{C}$ \\
Calculated minimum & $0.038 \mathrm{~m} / \mathrm{s} @ 600^{\circ} \mathrm{C}$ \\
fluidization velocity & $0.036 \mathrm{~m} / \mathrm{s} @ 700^{\circ} \mathrm{C}$ \\
& $0.034 \mathrm{~m} / \mathrm{s} @ 800^{\circ} \mathrm{C}$ \\
\hline & $\mathrm{P} 1 / \mathrm{T} 1: 0.023 \mathrm{~m}$ \\
Pressure and & $\mathrm{P} 2 / \mathrm{T} 2: 0.143 \mathrm{~m}$ \\
temperature & $\mathrm{P} 3 / \mathrm{T} 3: 0.238 \mathrm{~m}$ \\
measurement & $\mathrm{P} 4 / \mathrm{T} 4: 0.538 \mathrm{~m}$ \\
locations & $\mathrm{P} 5 / \mathrm{T} 5: 0.838 \mathrm{~m}$ \\
\hline
\end{tabular}

The mass of the bed particles was $2.355 \mathrm{~kg}$, corresponding to a static bed height of $20 \mathrm{~cm}$. For the temperatures of $700^{\circ} \mathrm{C}$ and $800^{\circ} \mathrm{C}$ additional test runs were carried out, for these runs a mix of agglomerates of different sizes was introduced to the bed together with the bed materials. The mass of agglomerates was $116 \mathrm{~g}$ corresponding to a bed agglomeration of $5 \%$ by weight. The agglomerates were produced from previous performed gasification experiments (Furuvik et al, 2020). Detailed specification of the properties of the bed material and the agglomerates are shown in Table 2.

Table 2. Specification of particle properties.

\begin{tabular}{|l|l|}
\hline Particle properties & Value \\
\hline Mass of bed material & $2.355 \mathrm{~kg}$ \\
\hline Bed material particle size range & $180-710 \mu \mathrm{m}$ \\
\hline Particle density of bed material & $2600 \mathrm{~kg} / \mathrm{m}^{3}$ \\
\hline Mass of agglomerates & $116 \mathrm{~g}$ \\
\hline Size of agglomerates & $1.0-3.0 \mathrm{~cm}$ \\
\hline Agglomerate density & $1510 \mathrm{~kg} / \mathrm{m}^{3}$ \\
\hline
\end{tabular}

\section{Simulation model}

\subsection{CPFD model description}

CPFD simulations are useful tools in modelling of fluidparticle interaction in fluidized bed reactors. In this study, the commercial software package Barracuda VR was used to simulate the fluid dynamics in a $20 \mathrm{~kW}$ laboratory scale bubbling fluidized bed system. Barracuda VR uses the three-dimensional Multiphase Particle-in-Cell (3D-MP-PIC) method for calculating the fluid-particle flow. The method is based on the
Eulerian-Lagrangian approach, wherein the Eulerian approach is used for solving the continuum phase and the Lagrangian approach is used for solving the particle phase. In the MP-PIC method, the solid particles are modeled as computational particles with a proper size and density distribution (Jayarathna et al, 2017; Thapa and Halvorsen, 2014). The governing equations include the conservation of mass, momentum and energy in the system. The interphase momentum transfer is an important term when modelling fluidized bed systems, and is described in details by Chladek et al. (Chladek et $a l, 2018$ ) and Jayarathna et al. (Jayarathna et al, 2017).

The particle fluidization results from the drag forces exerted by the fluid on the particles. The drag forces are the main cause of transfer of mass, momentum and energy between the different phases in the fluidized bed system (Marchelli et al, 2020). In Barracuda VR the drag forces $(\mathrm{F})$ have their general form:

$$
F=m_{p} D\left(u_{f}-u_{p}\right)
$$

Where $m_{p}$ is the mass of the particles, $u_{f}$ is the fluid velocity, $u_{p}$ is the particle velocity and $D$ is the drag function (CPFD Software, 2020). The dimensionless drag function is the fluid-particle interphase exchange coefficient and differs for the different drag models. Common for all systems are that D always has a complex dependency on the bed porosity and the particle Reynolds number (Re) (Marchelli et al, 2020). The $\mathrm{Re}$ is defined as:

$$
R e=\frac{2 r_{p} \rho_{f}\left(u_{f}-u_{p}\right)}{\mu_{f}}
$$

Where $r_{p}$ is the particle radius, $\rho_{\mathrm{f}}$ is the fluid density and $\mu_{\mathrm{f}}$ is the fluid viscosity. The drag models determine the drag forces acting on the particles, and several drag models are available in Barracuda. In order to study the behavior of different drag models for the chosen system, the Wen-Yu drag model (CPFD Software, 2020; Wen and $\mathrm{Yu}, 1966$ ), the Ergun drag model (CPFD Software, 2020; Ergun, 1952) and the Wen-Yu/Ergun drag model (CPFD Software, 2020) were tested.

The Wen-Yu model is considered most valid for dilute systems. The drag function for the Wen-Yu model $\left(\mathrm{D}_{\mathrm{WY}}\right)$ is dependent on the fluid conditions and the particle properties, and is related to the drag coefficient $\left(\mathrm{C}_{\mathrm{d}}\right)$ (CPFD Software, 2020; Wen and Yu, 1966):

$$
D_{W Y}=\frac{3}{8} C_{d} \frac{\rho_{f}\left(u_{f}-u_{p}\right)}{\rho_{p} r_{p}}
$$

Where $\rho_{\mathrm{p}}$ is the particle density.

The drag coefficient $\left(C_{d}\right)$ is defined as a function of $\mathrm{Re}$ and is calculated by the following set of equations (CPFD Software, 2020; Wen and Yu, 1966): 


$$
C_{d}=\left\{\begin{array}{cc}
\frac{24}{R e} \theta_{f}^{n_{0}} & R e<0.5 \\
\frac{24}{R e} \theta_{f}^{n_{0}}\left(c_{0}+c_{1} R e^{n_{1}}\right) & R e \leq 0.5 \leq 10000 \\
c_{2} \theta_{f}^{n_{0}} & R e>10000
\end{array}\right.
$$

Where $\theta_{\mathrm{f}}$ is the fluid volume fraction, $\mathrm{c}_{0}, \mathrm{c}_{1}, \mathrm{c}_{2}, \mathrm{n}_{0}$ and $\mathrm{n}_{1}$ are model constants with default values 1.0, 0.15, 0.44, -2.65 and 0.687 respectively.

The Ergun drag model is developed from dense bed data and is primarily most suitable for picturing flow through static packed beds. The drag function $\left(D_{E}\right)$ is given by (CPFD Software, 2020; Ergun, 1952):

$$
D_{E}=0.5\left(\frac{k_{1} \theta_{p}}{\theta_{f} R e}+k_{0}\right) \frac{\rho_{f}\left(u_{f}-u_{p}\right)}{\rho_{p} r_{p}}
$$

Where $\theta_{\mathrm{p}}$ is the particle volume fraction, $\mathrm{k}_{0}$ and $\mathrm{k}_{1}$ are constants with default values 2 and 180 respectively.

Wen-Yu/Ergun drag model is a combination of the Wen-Yu and the Ergun models. This allows it to be able to work well in both dense and dilute systems. The drag function $\left(\mathrm{D}_{\mathrm{WYE}}\right)$ is controlled by the close pack volume fraction $\left(\theta_{\mathrm{cp}}\right)$ with a switch from Ergun to Wen-Yu at defined values. Wen-Yu/Ergun uses the Ergun function for $\theta_{\mathrm{p}}>0.85 \cdot \theta_{\mathrm{cp}}$ and the Wen-Yu function at higher voidage (CPFD Software, 2020).

$$
D_{W Y E}=\left\{\begin{array}{cc}
D_{W Y} & \theta_{p}<0.75 \theta_{c p} \\
D_{E_{-} W Y} & 0.75 \theta_{c p} \geq \theta_{p} \geq 0.85 \theta_{c p} \\
D_{E} & \theta_{p}>0.85 \theta_{c p}
\end{array}\right.
$$

Where $\mathrm{D}_{\mathrm{E}_{-} w \mathrm{Y}}$ is defined as:

$$
D_{E_{-} W Y}=\left(D_{E}-D_{W Y}\right)\left(\frac{\theta_{p}-0.75 \theta_{c p}}{0.85 \theta_{c p}-0.75 \theta_{c p}}\right)+D_{W Y}
$$

\subsection{CPFD simulations}

CPFD simulations of a $20 \mathrm{~kW}$ laboratory scale fluidized bed were performed. The 3D computational grid was created using 10000 control volumes. The reactor was initially loaded with silica sand particles with mean particle diameter of $305 \mu \mathrm{m}$ and a particle density of $2600 \mathrm{~kg} / \mathrm{m}^{3}$. The particle size distribution is determined based on the discrete mass frequency distribution (Crowe et al, 2012), the result is shown in Figure 4.

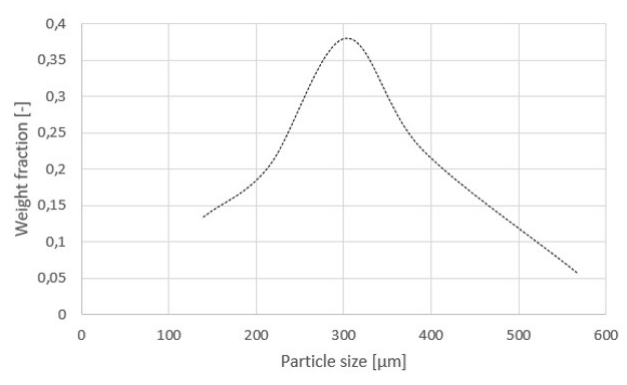

Figure 4. Particle size distribution of bed material.

Fluidizing agent was air at atmospheric pressure. Flow boundary conditions were applied at the bottom of the reactor. The pressure in the bed was measured at positions $\mathrm{P} 1=0.023 \mathrm{~m}, \mathrm{P} 2=0.103 \mathrm{~m}$ and $\mathrm{P} 3=0.183 \mathrm{~m}$ above the bottom of the column. The simulations were run for $70 \mathrm{~s}$ with a time step of $0.0001 \mathrm{~s}$. Table 3 shows the values of the model parameters used in the simulations. In order to add agglomerates to the fluidized bed a coarser grid was required, and the number of grid cells was therefore reduced from 10000 to 5120 . The size of the agglomerates was limited by the chosen grid, which allowed a maximum particle size of $1.0 \mathrm{~cm}$. In the present simulations, the size of the agglomerates ranged from $0.5 \mathrm{~cm}$ to $1.0 \mathrm{~cm}$ with a particle density approximately equal to $1510 \mathrm{~kg} / \mathrm{m}^{3}$ (Furuvik et al, 2019).

Table 3. Model parameters used in the CPFD simulations.

\begin{tabular}{|l|l|}
\hline Description & Value \\
\hline Particle density & $2600 \mathrm{~kg} / \mathrm{m}^{3}$ \\
\hline Fluidizing agent & Air \\
\hline Type of flow & $\begin{array}{l}\text { Isothermal@ } \\
300,600,700 \text { and } 800^{\circ} \mathrm{C}\end{array}$ \\
\hline Particle size & $\begin{array}{l}\text { Range: } 180-710 \mu \mathrm{m} \\
\text { Mean diameter: } 305 \mu \mathrm{m}\end{array}$ \\
\hline $\begin{array}{l}\text { Close-pack volume } \\
\text { fraction }\end{array}$ & 0.6 \\
\hline Particle sphericity & 0.86 \\
\hline Static bed height & $0.20 \mathrm{~m}$ \\
\hline $\begin{array}{l}\text { Superficial gas } \\
\text { velocity }\end{array}$ & $0.005-0.200 \mathrm{~m} / \mathrm{s}$ \\
\hline $\begin{array}{l}\text { Agglomerate particle } \\
\text { size }\end{array}$ & $1.0 \mathrm{~cm}$ \\
\hline Agglomerate density & $1510 \mathrm{~kg} / \mathrm{m}^{3}$ \\
\hline
\end{tabular}

\section{Results and discussion}

The bed pressure drop was measured experimentally at different superficial gas velocities. The operating temperatures were $300^{\circ} \mathrm{C}, 600^{\circ} \mathrm{C}, 700^{\circ} \mathrm{C}$ and $800^{\circ} \mathrm{C}$. Figure 5 shows that the pressure drops decrease with increasing bed temperatures. The drag equations explain 
how the bed operating temperature alters the fluidized conditions in the bed. All drag functions indicate that the drag forces are strongly dependent on both the bed porosity and the Re. Moreover, increased bed temperature results in increased fluid viscosity $\left(\mu_{\mathrm{f}}\right)$ and decreased fluid density $\left(\rho_{\mathrm{f}}\right)$, and hence lower Re. From the Wen-Yu drag functions, equation (3) and (4), it is obvious that changing the Re will cause a change in the magnitude of drag forces exerted on the bed particles. Stronger drag forces acting on the bed material give lower pressure drop in the fluidized bed.

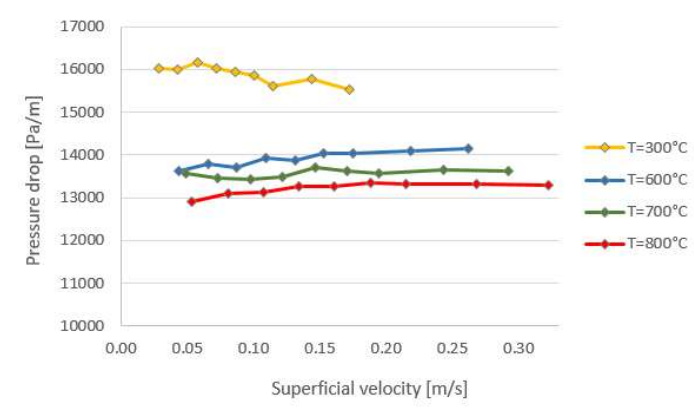

Figure 5. Comparison of experimental bed pressure drops with different operating temperatures.

Additional two fluidization experiments were carried out, where $5 \mathrm{wt} \%$ of agglomerates were mixed together with the bed particles. The experimental temperature conditions were $700^{\circ} \mathrm{C}$ and $800^{\circ} \mathrm{C}$. Figure 6 shows that adding agglomerates to the process alters the character of the fluidized conditions. This can also be seen in drag force calculations using the drag functions described in equation (3), (5) and (7). The drag functions describe how the relation between the superficial velocity and the particle shape, size and density determine the bed conditions during fluidization.

The agglomerates are relatively big, but porous, which give them low particle density $\left(\rho_{\mathrm{p}}\right)$. A change in the $\rho_{\mathrm{p}}$ alters the gravitational forces acting on the particles. Looking at the drag equations, lower $\rho_{\mathrm{p}}$ gives increased drag function that further results in stronger drag forces and decreased pressure drop.

The agglomerates are more angular compared to the sand particles. Lower sphericity alters the packing properties of the bed and leads to change in the associated void spaces. Larger voids in the bed result in higher fluid volume fraction, which based on the Wen$\mathrm{Yu}$ drag coefficient give increased drag forces and thereby lower bed pressure drop.

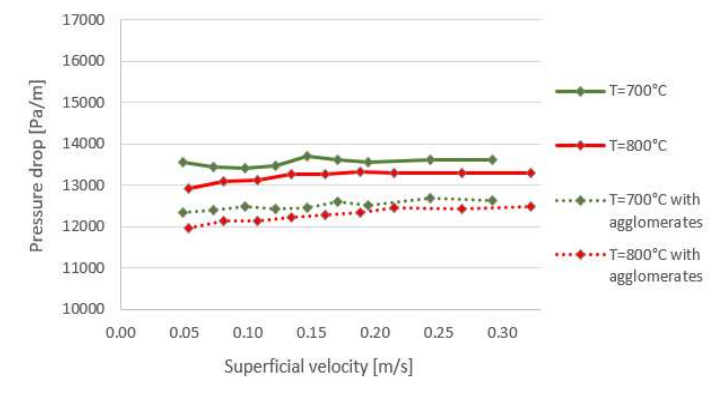

Figure 6. Comparison of experimental bed pressure drops with and without agglomerates.

To predict the fluidized conditions in the bubbling fluidized bed, the experimental setup was modeled using CPFD calculations. The simulation model was validated by comparing the measured pressure drop from experiments with results from the CPFD simulations. Wen-Yu, Ergun and the combined Wen$\mathrm{Yu} /$ Ergun drag models were tested in order to study the behavior of the different drag models for the present system. Figure 7 compares the experimental results and the results from the simulations of the three different CPFD models at bed temperature of $300^{\circ} \mathrm{C}$. The results show that the Wen-Yu drag function gives better prediction compared to the other drag models.

The advantage of Wen-Yu is that the drag force only depends on the fluid volume fraction and the Re, which make it very suitable for predicting the fluid dynamics in stabilized systems with isothermal bed conditions. The Wen-Yu drag function is based on a dependence on the Re, with a switch between different functions for $\operatorname{Re}<0.5$ and $\operatorname{Re}>1000$. Re increases as the superficial fluid velocity increases. However, Re will never exceed 1000 nor fall below 0.5 in the selected superficial velocity range. For this system, Wen-Yu therefore uses the same equation to calculate the bed conditions for all measuring points during the simulations. As the bed temperature is kept constant during the whole simulation time, it can be assumed that both the fluid conditions and the particle properties are unchanged. Fluid volume fraction will admittedly fluctuate slightly as a result of where and how bubbles are formed in the bed. These fluctuations are relatively small, hence they will not give large disturbances in the fluidized conditions.

Ergun drag model is based on data from fixed bed experiments and is therefore expected to be more appropriate at higher packing fractions. The superficial fluid velocity has large contribution to Ergun equation. For low velocities, the bed conditions are mainly controlled by the particle packing. As the superficial velocity increases, the velocity takes more control over the bed conditions. At higher velocities, Ergun gives large fluctuations in the pressure drop. As seen in Figure 7, the drag model fails in the fluidized regime.

Wen-Yu/Ergun drag model is a combination of the Wen-Yu model and the Ergun model, whereas the close- 
pack volume fraction $\left(\theta_{\mathrm{cp}}\right)$ determines which drag function that are used. For this system with $\theta_{\mathrm{cp}}=0.6$, the Ergun equation is applied when the particle volume fraction $\left(\theta_{\mathrm{p}}\right)>0.51$, and Wen-Yu is applied when $\theta_{\mathrm{p}}<$ 0.45 . The results indicate that the only drag function used for the present CPFD calculations is Ergun, which explains why the simulated pressure drop for Ergun and Wen-Yu/Ergun drag models are about the same.

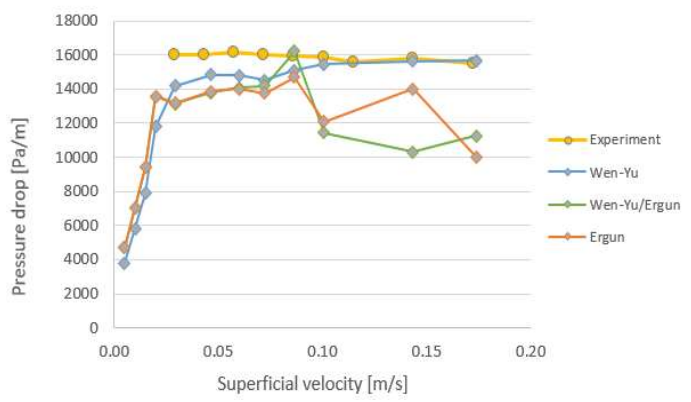

Figure 7. Comparison of experimental result and simulations using different drag models.

Figure 8 shows the experimental and the simulated pressure drops in the fluidized bed for temperature conditions of $300^{\circ} \mathrm{C}$. The theoretical minimum fluidization velocity $\left(\mathrm{u}_{\mathrm{mf}}\right)$ for the particles was previously calculated to $u_{m f}$,theoretical $=0.05 \mathrm{~m} / \mathrm{s}$. From the CPDF simulations, the minimum fluidization velocity is found at approximately the same value, $\mathrm{u}_{\text {mf,simulated }}=0.05$ $\mathrm{m} / \mathrm{s}$. Comparison of the experimental pressure drop and the simulations using the Wen-Yu drag model shows that the CPFD model can predict fluid dynamic behavior of fluidized bed reasonably well.

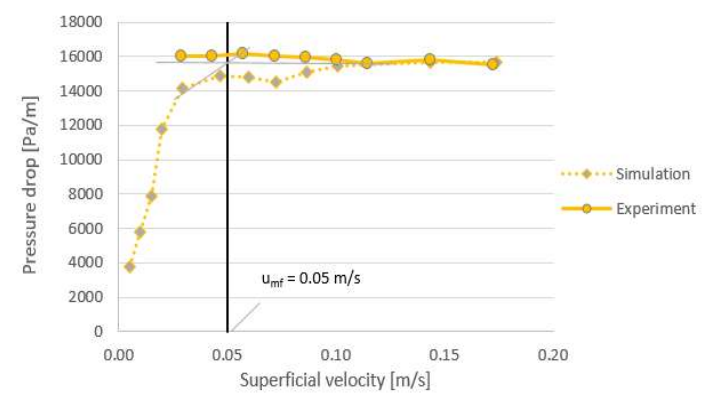

Figure 8. Comparison of experimental and simulated bed pressure drops for $300^{\circ} \mathrm{C}$.

Figure 9 shows the experimental and the simulated pressure drops in the fluidized bed for temperature conditions of $800^{\circ} \mathrm{C}$. As seen in the figure, the minimum fluidization velocities have decreased with the increased temperature. $\mathrm{u}_{\mathrm{mf}}$ is indicated by black vertical lines in the figure, which read off $u_{\mathrm{mf}}$,theoretical $=0.034 \mathrm{~m} / \mathrm{s}$ and $\mathrm{u}_{\mathrm{mf} \text {,simulated }}=0.046 \mathrm{~m} / \mathrm{s}$. The large deviation between $\mathrm{u}_{\mathrm{mf} \text {,theoretical }}$ and $\mathrm{u}_{\mathrm{mf} \text {,simulated }}$ can be explained by the theoretical calculation using the mean particle diameter of $305 \mu \mathrm{m}$, while the CPFD calculation use the particle size distribution (Figure 4) where the particle diameter ranges from 180-710 um. However, the CPFD simulation correctly predicts the fluidized regime and pressure drops in the fluidized bed system.

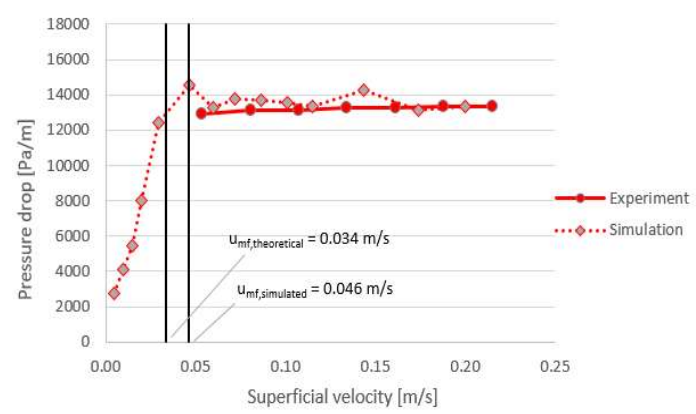

Figure 9. Comparison of experimental and simulated bed pressure drop at $800^{\circ} \mathrm{C}$.

Figure 10 and 11 compare the experimental and the simulated pressure drops for fluidization of sand and sand mixed with agglomerates for the temperature conditions of $700^{\circ} \mathrm{C}$ and $800^{\circ} \mathrm{C}$ respectively. One problem in the application of CPFD modelling of the agglomerated fluidized bed systems is that the agglomerates exist in all types of size, shapes and structures, which makes it difficult to define the agglomerated particles properties correctly. Although the simulations show instabilities in the fluidized regimes, the CPFD model maintains good agreement for the fluidized operation conditions in the fluidized regime.

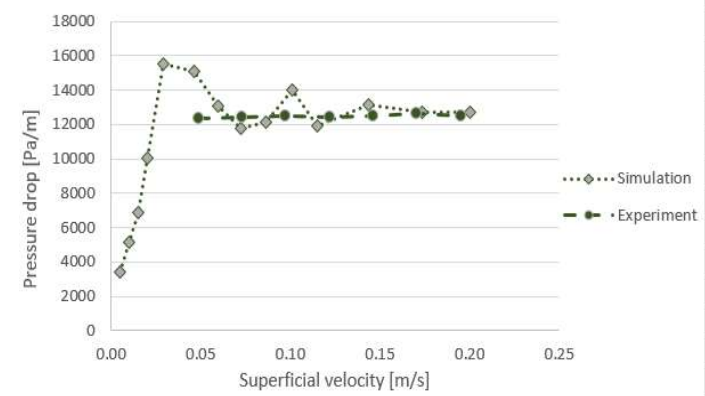

Figure 10. Comparison of experimental and simulated pressure drop for agglomerated bed at $700^{\circ} \mathrm{C}$.

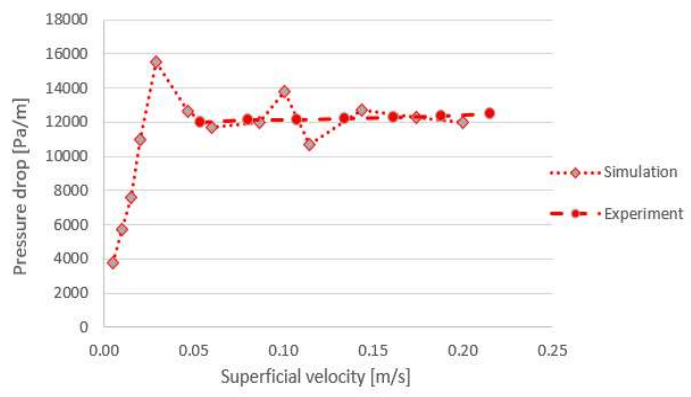

Figure 11. Comparison of experimental and simulated pressure drop for agglomerated bed at $800^{\circ} \mathrm{C}$. 


\section{Conclusion}

In this study, the fluid dynamics of a bubbling fluidized bed gasification system were investigated computationally and experimentally. The study included CPFD simulations of fluidization of silica sand particles and agglomerates using the commercial simulation software Barracuda VR version 17.4.1. Comparison of experimental and simulated pressure drops over the bed showed that the model can predict fluid dynamic behavior of fluidized bed reasonably well. Furthermore, the comparison showed that the Wen-Yu drag model gave better prediction of the fluidized conditions in the bed compared to the Ergun and the Wen-Yu/Ergun drag models.

The agglomerates are large sized and porous, which give them low density. The fluid dynamics in the bed depend upon the particle shape, size, density and diameter. Thus, the agglomeration process disturbs the fluidized conditions in the bed. The CPFD model is well capable of predicting the effect of agglomerates on flow behavior in a fluidized bed gasifier, and can be used for further studies including ash from different types of biomass.

\section{Acknowledgements}

This work is funded by the Research Council of Norway, Program for Energy Research (ENERGIX). Project 280892 FLASH - Prediction of FLow behavior of ASH mixtures for transport biofuels in the circular economy.

\section{References}

M. Bartles, W. Lin, J. Nijenhuis, F. Kapteijn and R. Ommen. Agglomeration in fluidized beds at high temperaures: Mechanisms, detection and prevention. Progress in Energy and Combustion Science 34:633-666, 2008.

P. Basu. Biomass Gasification, Pyrolysis and Torrefaction, Second Edition. Academic Pess, UK, 2013.

S. C. Capareda. Introduction to Biomass Energy Conversions. CRC Press, Boca Raton, US, 2014. ISBN: 978-1-46651334-1 (eBook-PDF).

J. Chladek, C. K. Jayarathna, B. M. E. Moldestad and L- A. Tokheim. Fluidized bed classification of particles of different size and density. Chemical Engineering Science 177: 155-162, 2018.

CPFD Software, LLC. Barracuda VR Solutions, (2020). Available from: https://cpfd-software.com/barracuda-vrsolutions/barracuda-vr (Accessed July, 2020)

C. T. Crowe, J. D. Schwarzkopf, M. Sommerfield and Y. Tsuji. Multiphase Flows with Droplets and Particles, Second Edition. CRC-Press, USA, 2012.

S. Ergun. Fluid flow through packed columns. Chemical Engineering Progress, 48: 89, 1952.

N. C. I. S. Furuvik, R. Jaiswal and B.M.E. Moldestad. Experimental study of agglomeration of grass pellets in fluidized bed gasification. WIT Transactions on Ecology and the Environment, 246, 2020.
N. C. I. S. Furuvik, R. Jaiswal and B. M. E. Moldestad. Flow behavior in an agglomerated fluidized bed gasifier. International journal of Energy and Environment 10(2):5564, 2019.

C. K. Jayarathna, B. M. E. Moldestad and L. A. Tokheim. Validation of results from Barracuda ${ }^{\circledR}$ CFD modelling to predict minimum fluidization velocity and pressure drop of Geldart A particles. Proceedings of the 58th SIMS conference, 2017.

D. Kunii and O. Levenspiel. Fluidization Engineering, Second Edition. Butterworth-Heinemann, USA, 1994

F. Marchelli, Q. Hou, B. Bosio, E. Arato and A. Yu. Comparison of different drag models in CFD-DEM simulations of spouted beds. Powder Technology 360:12531270, 2020.

S. K. Sansaniwal, K. Pal, M. A. Rosen and S. K. Tyagi. Global challenges in the sustainable development of biomass gasification: An overview. Renewable and Sustainable Energy Reviews 80: 23-43, 2017.

R. K. Thapa and B. M. Halvorsen. Study of Flow Behavior in Bubbling Fluidized Bed Biomass Gasification Reactor using CFD simulation. The 14th International Conference on Fluidization - From Fundamentals to Products, Eds, ECI Symposium Series, 2013.

E. Tiffault, S. Sokhansanj, M. Ebadian, H. Rezaei, E. O. B. Ghiasi, F. Yazdanpanah, A. Asikainen and J. Routa. Biomass pre-treatment for bioenergy. Case study 2: Moisture, physical property, ash and density management as pre-treatment practices in Canadian forest biomass supply chains. IEA Bioenergy, 2018.

C. Wen and Y. Yu. Mechanics of fluidization. Chemical Engineering Progress Symposium Series, 62: 100-111, 1966.

L. C. Williams, T. L. Westover, R. M. Emerson, J. S. Tumuluru and C. Li. Sources of Biomass Feedstock Variability and the Potential Impact on Biofuels Production. Bioenergy Resource 9: 1-14, 2016.

M. Öhman, A. Nordin, B.J Skrifvars, R. Backman and M. Hupa. Bed Agglomeration Characteristics during Fluidized Bed Combustion of Biomass Fuels. Energy \& Fuels 14(1): 169-178, 2000. DOI: 10.1021/ef990107b

M. Öhman and A. Nordin. The Role of Kaolin in Prevention of Bed Agglomeration during Fluidized Bed Combustion of Biomass Fuels. Energy \& Fuels 14(3): 618-624, 2000. DOI: $10.1021 / \mathrm{ef} 990198 \mathrm{c}$ 